\section{Digit-length ratios (2D:4D) as a phenotypic indicator of in utero androgen exposure is not prognostic for androgenic alopecia: a descriptive-analytic study of 1200 Iranian men.}

\author{
Amir Feily, ${ }^{1}$ Masoomeh Hosseinpoor, ${ }^{1}$ Ali \\ Bakhti, ' Mohamad Nekuyi, \\ Saeed Sobhanian, ${ }^{2}$ Zahra Fathinezhad, ${ }^{3}$ \\ Reza Sahraei, ${ }^{4}$ Marigdalia K. Ramirez-Fort ${ }^{5}$ \\ 'Department of Dermatology, Jahrom \\ University of Medical Sciences, Jahrom, \\ Iran; ${ }^{2}$ Hormozgan University of Medical \\ Sciences, Bandarabas, Iran; ${ }^{3}$ Department \\ of Community Health, Jahrom University \\ of Medical Sciences, Jahrom, Iran; \\ ${ }^{4}$ Department of Anesthesiology, Jahrom \\ University of Medical Sciences, Jahrom \\ Iran; 5Department of Dermatology, Tufts \\ Medical Center, Boston, MA, USA
}

\section{Abstract}

The etiology of androgenic alopecia (AGA) involves several factors, including genetics, androgens, age and nutrition. Digit-length ratio of the index and ring finger (2D:4D) is an indicator of prenatal exposure to sex hormones. There is a paucity of studies that systemically review the possible positive predictive value of 2D:4D in the development of AGA. We performed a single-site, descriptive-analytical study among a racially homogeneous population. Our results revealed that no significant association was determined between right 2D:4D and AGA severity within our entire population $(\mathrm{P}=0.384, \mathrm{r}=0.025)$, however a positive correlation coefficient was identified in subjects above the age of 40 . Based on the receiver operating characteristic curve analysis, 2D:4D does not predict the development of AGA. AGA is truly a multifactorial disease. Further, our findings suggest that increased in utero exposure to androgens as a fetus does not predispose men to develop AGA.

\section{Introduction}

Androgenic alopecia (AGA) is the most common type of progressive hair loss. The etiology of AGA involves several factors, including genetics, androgens, age and nutrition. ${ }^{1-4}$ Some evidence suggests that the digit-length ratio of the index and ring finger (2D:4D) is an indicator of prenatal exposure to sex hormones, with a lower 2D:4D being suggestive of a greater androgen exposure..$^{5-8}$

Digit-length ratios have been utilized to determine the effects of prenatal androgen exposure a variety of phenotypic expressions. ${ }^{5,6,8}$ However, there is a paucity of studies that systemically review the possible positive predictive value of $2 \mathrm{D}: 4 \mathrm{D}$ in the development of AGA.

\section{Materials and Methods}

The study was initiated after approval by the research and ethics committee of Jahrom University of Medical Sciences, approval ID: JUMS.REC.1393.017. All participants signed an informed consent prior to participating in the study. We performed a single-site, descriptiveanalytical study between June 2013 and February 2014 among a racially homogeneous population that they were selected by stratified and randomized sampling. Participants did not have a significant history of other types of alopecia (e.g. iatrogenic scarring alopecia, alopecia areata, etc.). A trained team performed digit-length measurements of both hands with vernier calipers and subsequently calculated the 2D:4D. A single trained technician graded baldness using the HamiltonNorwood Classification scale; for simplicity these grades were further divided into four stages: no baldness (I), mild (II, III), moderate (IV, V) and severe baldness (VI, VII).

Associations between 2D:4D and AGA were determined with SPSS version 16. The quantitative results are presented as a mean \pm standard deviation (SD). A Pearson linear correlation was performed to assess relationships between 2D:4D and age; a Spearman linear correlation to assess relationships between 2D:4D and AGA severity, and ROCs mode was used to measure the validity of 2D:4D as a predictive test for AGA. Statistical significance was assigned at $\mathrm{P}<0.05$.

\section{Results}

A total of 1200 men between 20 to 60 years of age with a mean age of 33.2 (SD: 0.28), enrolled in the study. The prevalence of AGA among the study population was $45.4 \%$. A total of $53.4 \%$ of the participants had normal hair distribution (aged 29.95 \pm 8.4 years), 26.16\% had mild hair loss (aged $34.97 \pm 10.11$ years), $15.19 \%$ had moderate (aged $40.35 \pm 9.43$ years) and $4.32 \%$ had severe hair loss (aged $42.28 \pm 9.92$ years)

The mean ratio of the right 2D:4D was 0.992 (SD: 0.0024), while the left was 0.982 (SD:
Correspondence: Masoomeh Hosseinpoor, Department of Dermatology, Jahrom University of Medical Sciences, Shahid Motahhari Blvd, Jahrom, Iran.

Tel.: +98.937.6925988.

E-mail: masoomehosseinpoor@yahoo.com

Key words: Androgenic alopecia; hair loss; digitlength ratio; predictive value.

Contributions: the authors contributed equally.

Conflict of interest: the authors declare no potential conflict of interest.

Received for publication: 24 December 2015 Accepted for publication: 4 April 2016.

This work is licensed under a Creative Commons Attribution-NonCommercial 4.0 International License (CC BY-NC 4.0).

\section{(C) Copyright Amir Feily et al., 2016}

Licensee PAGEPress, Italy

Dermatology Reports 2016; 8:6386

doi:10.4081/dr.2016.6386

0.0017). No significant differences were identified between left and right hand 2D:4D per subject (Table 1). There was significant association between age and $\operatorname{AGA}(\mathrm{r}=-0.426$, $\mathrm{P}=0.001$ ). No significant association was determined between right 2D:4D and AGA severity within our entire population $(\mathrm{P}=0.384, \mathrm{r}=0.025)$, also there was no significant association between left 2D:4D and AGA severity $(\mathrm{P}=0.495, \mathrm{r}=0.028)$, however a correlation coefficient was identified in subjects above the age of 40 .

The receiver operating characteristic (ROC) analysis of subjects age 40 and above demonstrated the area under curve (AUC) as 0.502 (95\%CI 0.391 to 0.613$)$ and $0.480(95 \% \mathrm{CI}$ 0.371 to 0.590 ) for right and left $2 \mathrm{D}: 4 \mathrm{D}$, respectively, as a predictive test for AGA (Figure 1).

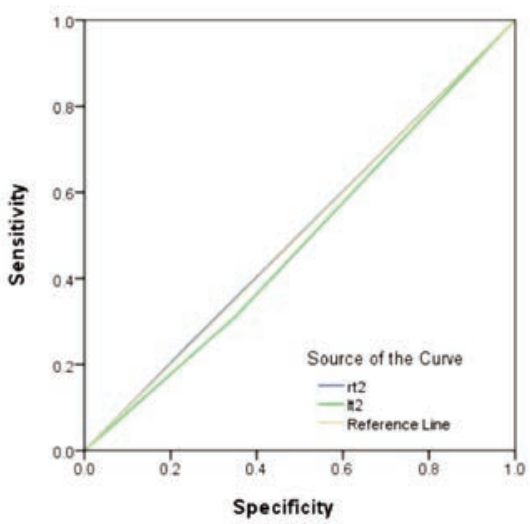

Figure 1. Receiver operating characteristic curve analysis of right and left 2D:4D with androgenetic alopecia gold standard. 
Table 1. Mean of $2 \mathrm{~d}: 4 \mathrm{~d}$ ratio compared to androgenetic alopecia stage severity.

\begin{tabular}{|c|c|c|c|c|c|c|c|c|}
\hline AA stages & Mean & SD & $95 \% \mathrm{CI}$ & Sum of squares & Df & Mean square & F & Sig. \\
\hline Right ratio & & & & 0.009 & 3 & 0.003 & 0.409 & 0.747 \\
\hline Normal & 0.9919 & 0.08179 & 0.9855-0.9982 & & & & & \\
\hline Mild & 0.9952 & 0.06994 & $0.9874-1.0030$ & & & & & \\
\hline Moderate & 0.9913 & 0.09576 & $0.9770-1.0057$ & & & & & \\
\hline Severe & 0.9810 & 0.13942 & $0.9391-1.0229$ & & & & & \\
\hline Left ratio & & & & 0.012 & 3 & 0.004 & 1.127 & 0.337 \\
\hline Normal & 0.9853 & 0.06019 & 0.9806-0.9899 & & & & & \\
\hline Mild & 0.9781 & 0.04175 & $0.9735-0.9828$ & & & & & \\
\hline Moderate & 0.9795 & 0.09040 & $0.9659-0.9931$ & & & & & \\
\hline Severe & 0.9812 & 0.03508 & $0.9707-0.9918$ & & & & & \\
\hline
\end{tabular}

$\mathrm{AA}$, androgenetic alopecia; SD; standard deviation; $\mathrm{Cl}$, confidence interval.

\section{Discussion and Conclusions}

Herein, is the largest study to date aimed to explore the utility of a phenotypic expression of in utero androgen exposure in predicting the development of AGA. The prevalence of AGA was $45.4 \%$, similar to worldwide reports..$^{9,10}$ The prevalence of AGA trended upwards as participant age increased. Although there was no significant association between right 2D:4D and AGA $(\mathrm{P}=0.384$, $\mathrm{r}=0.025)$, there was a correlation coefficient identified in subjects above the age of 40 . With increasing of age the AGA severity increases especially in participants above the age of 40 .

In clinical practice, most patients generally express AGA by age 40 . Therefore, we attempted to evaluate the utility of $2 \mathrm{D}: 4 \mathrm{D}$ as a predictive test for AGA. Based on the ROC curve analysis, 2D:4D does not predict the development of AGA. AGA is truly a multifactorial disease. Further, our findings suggest that increased in utero exposure to androgens does not predispose men to develop AGA.

\section{References}

1. Trueb RM. Molecular mechanisms of androgenetic alopecia. Exp Gerontol 2002;37:981-90.

2. Stárka L, Cermáková I, Dusková M, et al. Hormonal profile of men with premature balding. Exp Clin Endocrinol Diabetes 2004;112:24-8.

3. Chumlea WC, Rhodes T, Girman CJ, et al. Family history and risk of hair loss. Dermatology 2004;209:33-9.

4. Inui S, Itami S. Androgen actions on the human hair follicle: perspectives. Exp Dermatol 2012;22:168-71.

5. Honekopp J, Manning TJ, Muller C. Digit ratio (2D:4D) and physical fitness in males and females: evidence for effects of prenatal androgens on sexually selected traits. Horm Behav 2006;49:545-9.

6. Honekopp J, Voracek M, Manning JT. 2nd to 4th digit ratio (2D:4D) and number of sex partners: evidence for effects of prenatal testosterone in men. Psychoneuroen- docrinology 2006;31:30-7.

7. Manning JT, Wood S, Vang E, et al. Second to fourth digit ratio (2D:4D) and testosterone in men. Asian J Androl 2004;6:2115 .

8. Rivas MP, Moreira LM, Santo LD, et al. New studies of second and fourth digit ratio as a morphogenetic trait in subjects with congenital adrenal hyperplasia. Am J Hum Biol 2014;26:559-61.

9 . Severi G, Sinclair R, Hopper JL, et al. Androgenetic alopecia in men aged 40-69 years: revalence and risk factors. $\mathrm{Br} \mathrm{J}$ Dermatol 2003;149:1207-13.

10. Yeo IK, Jang WS, Min PK, et al. An epidemiological study of androgenic alopecia in 3114 Korean patients. Clin Exp Dermatol 2014;39:25-9. 